\title{
Thermal Performance Investigation of Heat Transfer Characteristics of a Two Phase Thermosyphon using Hybrid Nanofluid
}

\author{
Leena B. Pardeshi* and Nilesh C. Ghuge \\ Mechanical Engineering, SPPU, Matoshri college of Engineering and Research center, Nashik, India
}

Accepted 15 June 2016, Available online 20 June 2016, Special Issue-5 (June 2016)

\begin{abstract}
It is very important to increase the rate of Heat transfer in many areas especially in heat exchangers, gas turbine, air coolers, different power plant, where transfer of heat Energy is an important factor. A tremendous amount of effort had taken to develop new methods to increase heat transfer. It demonstrated that nanofluid can have remarkable higher rate of heat transfer than those of the base fluid. In this paper a thermal performance of a circular heat pipe with hybrid nanofluid (i.e. copper oxide and carbon nanotube) is carried out at different heat input, at different angle of inclination and at different concentration of nanoparticle on two phase closed thermosyphon. Result of this experiment shows that efficiency of HP increases with use of nanofluid. Maximum efficiency observed at inclination angle $75^{\circ}$ and it is $33.24 \%$.
\end{abstract}

Keywords: Thermal conductivity, nanofluid, Heat transfer enhancement, circular HP

\section{Introduction}

The importance of heat transfer enhancement has gained greater significance in many areas. Due to limitation of fossil fuel in the world, subject of energy consumption optimization in various industrial processes becomes very important. There are different techniques to transfer heat. In this paper experiment is carried out to determine rate of heat transfer through heat pipe. Heat pipe it is an device used to transfer heat from one point to another point by using the principle of thermal conductivity and phase transition. Among all heat transfer technique heat pipe is the most appropriate technology and it is very cost effective and having excellent heat transfer capability, high efficiency and structural simplicity.

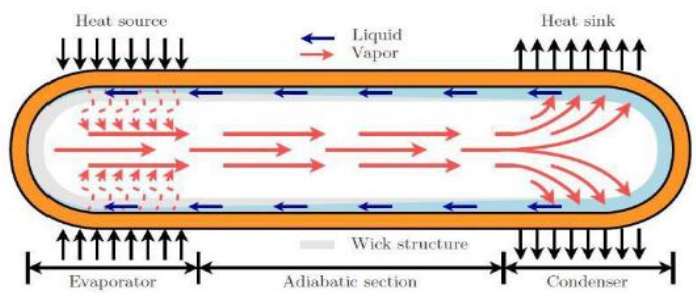

Fig.1: Technical description of HP

There are different type of Heat Pipe depends on the principle of coming back water from condenser to evaporator
Two phase closed thermosyphon: A two phase closed thermosyphon is wickless. In this type condenser section is places above the evaporator section and whatever is the base fluid from condenser section that come back into evaporator section by the action of gravity.

Capillary-Driven Heat Pipe: It contains wick type structure. And wick is place on the inner radius of the pipe wall and base fluid return to evaporator through wick structure by the capillary action.

Annular Heat Pipe: It is similar to Capillary-Driven Heat pipe only difference is that cross section of the vapor space in annular heat pipe is annular instead of circular. So because of increasing surface area the capillary limit is higher in this case.

Vapour chamber: It is flat plate heat pipe in a rectangular or disked shape. In this basically additional block between evaporator and condenser section is provided. Used in special case when condenser is below the evaporator.

This Experiment is carried out to determine Heat Transfer characteristics of a two phase closed thermosyphon.

Nanoparticle is the very fine size metal or nonmetal particle and when nanoparticle is associated with any base fluid is called nonofluid. Modern nanotechnology provides new opportunities to process and produce material with average crystallite sizes below $50 \mathrm{~nm}$. They offer new possibilities to enhance heat transfer performance compared to pure fluid. 
Because of larger surface area of nanoparticle not only heat transfer capability but also increases the stabilities. There are different nanofluid is been available like copper oxide ( $\mathrm{CuO}$ ), Aluminum oxide (AgO), Titanium oxide $\left(\mathrm{TiO}_{2}\right)$, Gold (Au), Silver (Ag), Copper $(\mathrm{Cu})$ etc.

There is different pair of heat pipe material and nanofluid. Different researchers had been worked on it and finally they specified the pair like-copper envelope and water as a working fluid, copper-R134a, Aluminium-NH3, Super alloy-P etc. This experiment is carried out experiment on copper as an envelope and water as a working fluid.

Many researchers worked on different pair of heat pipe with different nanofluid.

Amir Faghri[2014] worked on, Heat pipe: Review, opportunities and Challenges. He studied various heat pipes, operation of HP, heat transport limitation. He also provided a self contained document to design and simulate various types of heat pipe under different operating condition.

M.G.Mausa[2011] carried out an experiment on, an Effect of nanofluid in circular heat pipe. The nanofluid consists of $\mathrm{Al}_{2} \mathrm{O}_{3}$ with a diameter of $100 \mathrm{~nm}$. The experimental data of the nanofluid were compared with those of DI water. Experimental results showed that if the concentration of nanofluid increasing then thermal resistance of heat pipe decreasing.

Clement Kleinstreuer, Yu Feng[2011] worked on experimental and theoretical studies of nanofluid thermal conductivity enhancement. They foundthat metallic nanoparticle at low fractions in liquid, enhance the thermal conductivity over base fluid values and that's why they are potentially useful for advanced cooling of micro-system.

X.L.Shang, Z.H.Liu [2008] investigated the heat transfer characteristics of a closed loop heat pipe with copper as a nanoparticle and water as base fluid with different filling ratio. The results were compared with those of same heat pipe with distilled water as a base fluid. They found that by using $\mathrm{Cu}$-water nanofluid in a heat pipe enhance the heat removal capacity by $83 \%$. It was stated that directly adding the nanoparticle into the distilled water without and stabilizing agent had greater heat transfer enhancement compared to case where stabilizing agent is added.

S.Kang, W.Wei, S.Tsai and S.Yang[2006] carried out an experiment on, Study of nanofluid is employed as theworking medium for a conventional grooved circular heat pipe. The nanofluid used in this case is an aqueous solution of $35 \mathrm{~nm}$ diameter silver nanoparticle. The experiment was performed to measure temperature distribution and to compare heat pipe thermal resistance using nanofluid with water. He demonstrated that the thermal resistance decreased $10-80 \%$ compared to water. Also he found that thermal resistance of heat pipe decreases as silver nanoparticle size and concentration increases.

Salma Halefadi, Patrices Estelle, Thierry Mare [2014] worked on heat transfer properties of aqueous carbon nanotube nanofluid in coaxial heat exchanger under laminar regime. He found that thermal conductivity of a based fluid significant effect on enhance by using nanofluid.

C.Y.Tasi [2004] worked on, experiment on cylindrical mesh wick heat pipe. The working fluid was aqueous solution of various size gold nanoparticle. The experimental results showed that total resistance of heat pipe reduced $20-37 \%$ due to the addition of nanoparticle.

Y.H.Lin [2008] investigated on the thermal performance of closed loop oscillating heat pipe using using nanofluid. They applied water based silver nanofluid in different volume fraction and various filling ratio(20\%, 40\%, 60\%, and $80 \%)$. Results showed that the thermal performance of oscillating heat pipe using nanofluid was better than that of water. The best filling ratio was reported $60 \%$.

Jung-Shun chen, Jung-Hua Chou [2014] worked on cooling performance of flat plate heat pipe with different liquid filling ratio. In their work the effects of different liquid filling ratio also studied on the performance of flat plate HP. He found that the optimal liquid fill ratio for the FPHP was 25\% and maximum heat transport capacity reported $47 \mathrm{~W}$. He also said thattoo much or insufficient filling ratio would reduce the effective thermal conductivity of FPHP.

C.Wilson [2006] worked on experimental investigation to study the nanofluid effect on heat transport ability in an oscillating heat pipe. Their results demonstrated that the thermal performance of heat pipe was significantly improve when charged with water based diamond nanofluid with the thermal resistance decreased to $0.03^{0} \mathrm{C} / \mathrm{W}$ at a power input 336 W.

H.B.Ma[2006] investigated experimentally and theoretically that heat transfer performance of flat plate oscillating heat pipe, which were created by machining grooved on both side of copper plate. Acetone, water, diamond-acetone, gold-water and diamond water nanofluid were tested as working fluid. The thermal resistance was further decreased by using the nanofluid. It was found that high volume fraction diamond-water was not stable but settled with time and reduces thermal performance. Gabriela Huminic [2011] worked on the heat transfer characteristics of two thermosyphon with iron oxide nanofluid. He found that heat transfer capacity increases with an inclination angle and also the thermal resistance decrease with increase in inclination angle and it also increase in volume concentration. The heat pipe filled with nanofluids has more thermal efficiency, it is more stable and lower thermal resistance than heat pipe filled with water suggested by Senthilkumar [2011].

The results displayed that aqueous solution of $n-$ pentanol give better results than aqueous solution of $n$ butanol.

Wesley Williams [2008] worked on the turbulent convective heat transfer by using of alumina $\left(\mathrm{Al}_{2} \mathrm{O}_{3}\right)$ and zirconia $\left(\mathrm{ZrO}_{2}\right)$ nanoparticle in water of horizontal 
tube section at different flow rates. The results showed that there is an increase in heat transfer enhancement. Ulzie Rea [2009] worked on the laminar convective heat transfer and various pressure losses for aluminawater and zirconia-water nanofluid in a vertical tube. The outcomes showed that by using these nanofluids, the heat transfer coefficient increases by approximately $3 \%$ in the developed region and $2 \%$ in the entry region at $1.32 \%$ vol.

Yu-Tang chen [2010] worked on Experimental study of silver nanofluid on flat plate HP thermal performance. He found from his experiment that the temperature difference and thermal resistance of FHP with silver nanoparticle solution were lower than that of with pure water.

TusharTiwantane, ShivprakashBarve [2015] worked on Experimental study of WHR using Heat Pipe Heat Exchanger with Hybrid nanofluid. In his experiment he work on heat exchanger which is made up of Heat Pipe as an WHR and used nanofluid as $\mathrm{Al}_{2} \mathrm{O}_{3}$, $\mathrm{CuO}, \mathrm{TiO}_{2}$. And he concluded that the average increase in Nussle number for hybrid nanofluid is $10.94 \%$ when compared to pure water.

Kamble D.P., Gadhave P.S., M.A. Anwar [2014] worked on Enhancement of Thermal Performance of HP using Hybrid nanofluid. He used Hybrid nanofluid $\mathrm{Al}_{2} \mathrm{O}_{3}+\mathrm{CuO}$ and water as a base fluid. He found that thermal resistance reduces by $32 \%$ with $2 \%$ volume concentration. For the variation of heat input between $25 \mathrm{~W}$ to $100 \mathrm{~W}$ with $2 \%$ volume concentration the thermal resistance decrease by $39.28 \%$ with pure water.

Research Gap: Most of the researcher worked to enhance heat transfer to using nanofluid. But very less work is available on the effect of thermal performance using mixture of two nanofluid on HP.

So following are the main objectives of this work:

1. To find the impact of various operating parameter like power input, concentration of nanofluid on rate of heat transfer of nanofluid in HP.

2. To find thermal performance of HP for different angle of inclination.

3. To find thermal resistance of HP for different angle of inclination and for various concentration of HP.

\section{Experimental set up}

In this work experimental set up is used to describe the thermal performance of hybrid nanofluid which is flowing inside the HP along the water. Heat Pipe can be design by considering the Capillary limit, Sonic Limit, Boiling Limit, Entrainment limit and Vapor pressure limit.

The schematic of experimental set up is shown in Fig.2. The band type heater is provided to supply heat at the evaporator section. A $230 \mathrm{~V} \mathrm{AC} \mathrm{power} \mathrm{supply} \mathrm{is}$ given to heater. In the condenser section water jacket is provided. To determine the temperature at various location of heat pipe, J- type of thermocouples is provided. Here filling ratio is considered as $50 \%$.In this experiment the amount of heat loss from evaporator and condenser section is assumed to be negligible.

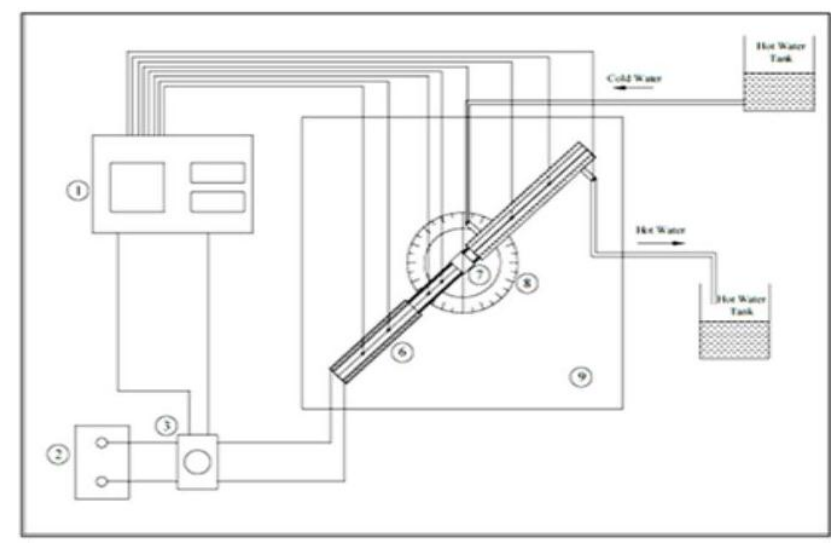

(1. Control panel 2. Electric supply 3. Dimmerstat 4. Heat pipe 5. Angle variation arrangement 6 . Angular scale 7 . Water tank 8. Thermocouple)

Fig.2 Layout of Experimental set up

Table 1 Parameters of Heat Pipe

\begin{tabular}{|c|c|c|}
\hline Sr.No. & Property & Value \\
\hline 1 & Evaporator Length & 0.1 \\
\hline 2 & Adiabatic Length & 0.05 \\
\hline 3 & Condenser Length & 0.45 \\
\hline 4 & Total Length & 0.6 \\
\hline 5 & Effective Length & 0.55 \\
\hline 6 & Outer Radius & 0.01252 \\
\hline 7 & Inner Radius & 0.011 \\
\hline 8 & Cross Section Area & 0.000379 \\
\hline 9 & Axial Angle & 90 \\
\hline 10 & $\begin{array}{c}\text { Thermal Conductivity of } \\
\text { Material (Copper) }\end{array}$ & 385 \\
\hline 11 & Vapor Core Radius & 0.011 \\
\hline 12 & $\begin{array}{c}\text { Evaporative Section } \\
\text { Radius }\end{array}$ & 0.011 \\
\hline 13 & $\begin{array}{c}\text { Condenser Section } \\
\text { Radius }\end{array}$ & 0.011 \\
\hline
\end{tabular}

Here basically four Heat Pipe is manufactured of a same dimension, same material. One is of pure water, $2^{\text {nd }}$ contain $1 \%$ hybrid nanofluid, $3^{\text {rd }}$ contain $2 \%$ and 
$4^{\text {th }}$ contain $3 \%$ of nanofluid. Power input to heat pipe is increased from a $25 \mathrm{~W}$. At a different tilt angle i.e.150, $30^{0}, 45^{0}, 60^{0}, 75^{0}$ reading is taken. Mass flow rate, into water jacket is also gradually increased.

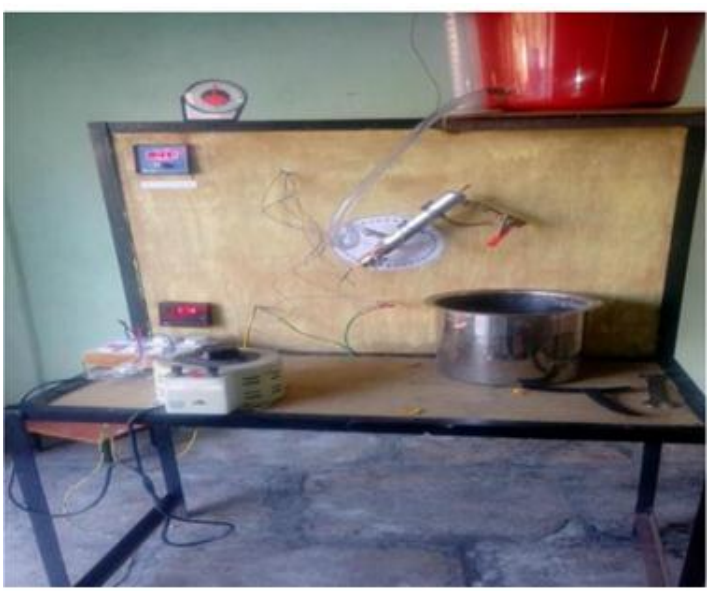

Fig.3 Experimental set up

\section{Data reduction}

Efficiency of HP given by:

$\eta=\frac{m C p \Delta T}{Q}$

Thermal Resistance of HP

$\mathrm{R}=\frac{T e-T c}{Q}$

Average Evaporative and condenser temperature is

$\mathrm{Te}=\frac{T 1+T 2}{2}$

$\mathrm{Tc}=\frac{T 5+T 6}{2}$

\section{Results and Discussion}

By doing the experiment we got following results:

1. HP with base fluid i.e. water at a $1 \mathrm{LPH}$ mass flow rate with different inclination angle i.e. $15^{0}, 30^{0}, 45^{0}$, $60^{0}, 75^{0}$

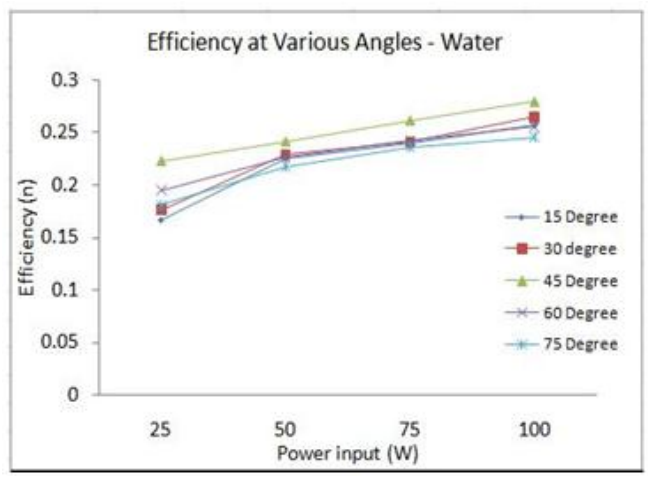

Fig.4 Effect of Angle of inclination on thermal efficiency

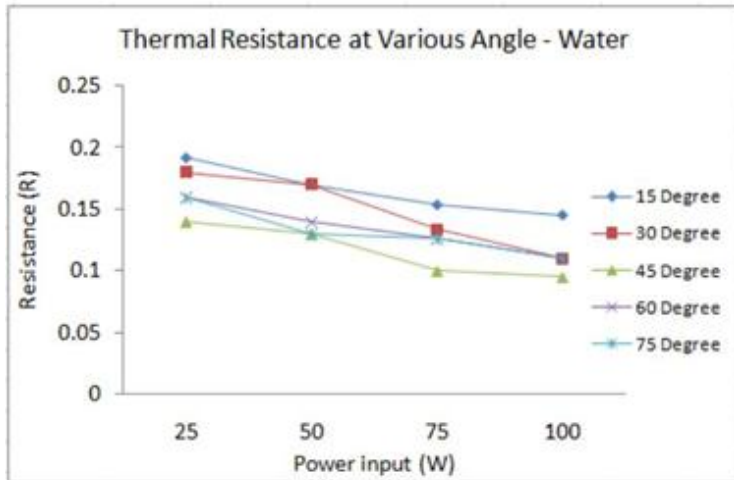

Fig.5 Effect of angle of inclination on thermal resistance

It is found that when HP is of water then at $15^{0}$ we get thermal efficiency $22.22 \%$, when angle is $30^{0}$ then $22.81 \%$, at $45^{0} 25.119 \%$, at $60^{0}$ efficiency is $23.02 \%$ and at $75^{0}$ efficiency is $22.03 \%$. Also the thermal resistance reported at $15^{\circ}, 30^{\circ}, 45^{\circ}, 60^{\circ}$, and $75^{0}$ is to be $0.16,0.14,0.11,0.13$, and 0.13 respectively.

2. At a $1 \%$ concentration of nanofluid at $1 \mathrm{LPH}$ with different angle i.e. $15^{0}, 30^{0}, 45^{0}, 60^{0}, 75^{0}$

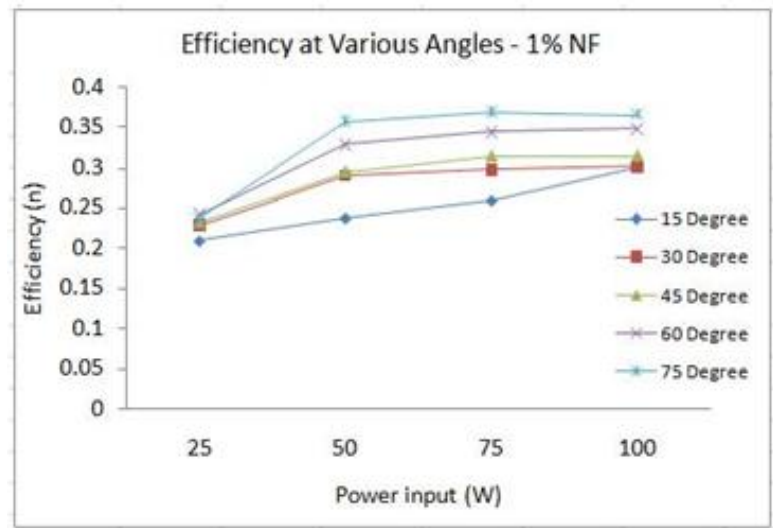

Fig.6 Effect of angle of inclination on thermal efficiency

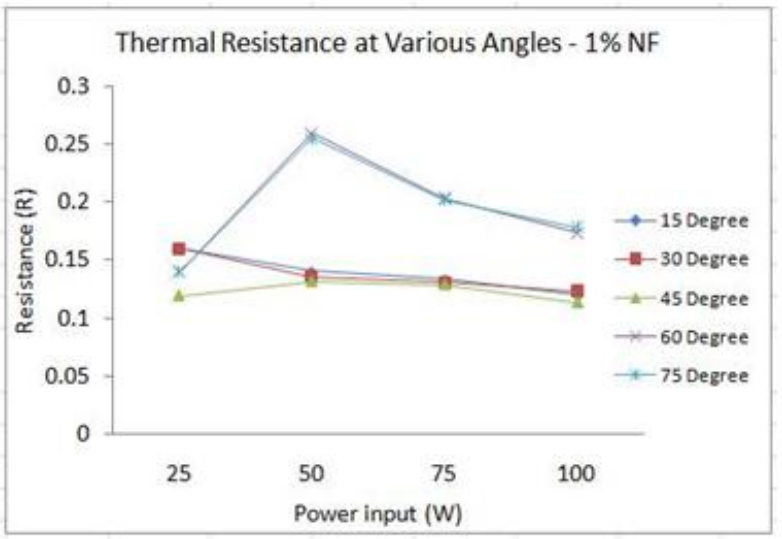

Fig.7 Effect of angle of inclination on thermal resistance 
It is found that when HP is of $1 \%$ nanofluid then at $15^{0}$ we get thermal efficiency $25.09 \%$, when angle is $30^{0}$ then $27.89 \%$, at $45^{0} 28.86 \%$, at $60^{\circ}$ the efficiency is $31.61 \%$ and at $75^{0}$ efficiency is $33.24 \%$. Also the thermal resistance at $15^{0}, 30^{\circ}, 45^{0}, 60^{\circ}$, and 750 found to be $0.138,0.13,0.123,0.194$, and 0.192 respectively.

\section{Conclusion}

1 From this experiment we found that thermal efficiency of HP increase with use of nanofluid.

In case of water as a base fluid thermal resistance get reduce as we increase angle of inclination.

We get maximum efficiency i.e. $33.24 \%$ when HP with nanofluid with orientation angle is $75^{\circ}$.

\section{Nomenclature}

$\eta=$ efficiency of heat pipe

$\mathrm{R}=$ thermal resistance of heat pipe

$\mathrm{Te}=$ Average temperature of evaporator

$\mathrm{Tc}=$ Average temperature of condenser

$\mathrm{Q}=$ Heat input

$\mathrm{M}=$ mass flow rete

$\mathrm{Cp}=$ specific heat of water

$\Delta \mathrm{t}=$ Temperature difference

$\mathrm{HP}=$ heat pipe.

\section{References}

Amir Faghari,(2014), HP: review, opportunities, Challenges Frontiers in HP, 5, 2155-2618

M.G.Mausa, (2011), Effect of nanofluid concentration on the performance of circular HP, Ain Shams Engg Journal, 2, 6369.

Clement Kleinstreuer, Yu.Feng, (2011), Experimental and theoretical studies of nanofluid thermal conductivity enhssancement:A Review, A Sringer Journal, 6, 1-13.

X.F.Shang, Z.H.Liu, (2008), Heat Transfer performance of a horizontal micro grooved HP using CuOnanofluid, Micromechanics and Micro engineering,l, 18,35-37.

S.W.Kang, W.C.Wei, S.H. Tasi, S. Y. Yang, (2006), Experimental investigation of silver nanofluid on HP thermal performance, Applied Thermal Engg., 1 26, 2377-2382.
Salma Halefadi, Patrice Estelle, Thierry Mare,(2014), Heat Transfer properties of acqueous carbon nanotube nanofluid in coaxial Heat Exchanger under laminar regime, Thermal and fluid science, 55, 174-186.

C.Y.Tsai, H.T. Chein, B.Chan, P.H. Chen, P.P.Ding, T.Y. Lub,(2004), Effect of structural character of gold nanoparticle in nanofluid on HP thermal performance, Mat Lett, 58, 1461-1465.

Y.H.Lin, S.W. Kang, H.L.Chen,(2008), Effect of silver nanofluid on pulsating HP thermal performance, Applied Thermal Engg., 2, 1312-1317.

Jung-Shun, Jung-Hua Chou,(2014), Cooling performance of flat plate HP with different liquid filling ratio, International Journal of Heat and mass Transfer, 77, 874-882.

H.B.Ma, C.Wilson, Q.Yu, K. Park, S.U.S. Choi, M.Trirumal, (2006), An experimental investigation of heattransportcapability in an oscillating HP, Applied Physics, 88,143-156.

H.B.Ma, C.Wilson, Q.Yu, K.Park, S.U.S. Choi, M.Tirumal, (2006), An Experimental investigation of heat transport capability in nanofluid oscillating HP, Journal of Heat transfer, 128, 1213-1216

Gabriela, Huminic, Angel Huminic, (2011), Heat transfer Characteristics of two phase closed thermosyphon using nanofluid, Experimental thermal and Fluid Science, 35, 550-557

RathinasamySenthikumar, Subaiah Vaidynathan, Balasubram anian Sivaraman, (2011), Thermal Analysis of HP using self Rewetting fluid, Thermal Science, 15, 879-888.

Vesley Williams, Lin Wen. Hu, Jacopo Buon-gioran,(2008) Experimental Investigation of Turbulent convective Heat Transfer and Pressure loss of Alumina/water and Zirconia/water nanoparticle colloids in horizontal Tubes", Journal of Heat Transfer, 130, 1-7

Ulzie Rea, Tom Mckrell, Lin-Wen $\mathrm{Hu}$, Jacopo Buongiorno, (2009), Laminar convective Heat transfer and viscous loss of Alumina-water and Zirconia-water nanofluid, International Journal of Heat and Mass transfer, 52, 2042 2048

Yu Tang Chen, (2010), Experimental study of silver nanofluid on flat HP thermal performance, Journal of Marine Science and Technology, 18, 731-734

TusharTiwatane, ShivprakashBarve,(2015), Experimental study of WHR using HP Heat Exchanger with Hybrid nanofluid, International Journal of Mechanical and Industrial Technology, 3, 40-47

KambleD.P., Gadhav P.S., M.A. Anwar, (2014), Enhancement of thermal performance of HP using HYBRID nanofluid, IJETT, 17, 425-428. 